\title{
Spinal anaesthesia for minor paediatric surgery
}

Our recent experience using spinal anaesthesia for paediatric surgical procedures is reviewed. In 1984, 30 patients aged seven weeks to 13 years were anaesthetised in this manner. Lumbar puncture failed in four of 34 patients, 12 required sedation during the operative course and 11 required light general anaesthesia to complete these procedures. Tetracaine one per cent or bupivicaine 0.75 per cent were the drugs used. During the procedure and depending on their age, the patients were either sedated or were distracted with the use of Disney cartoons played on a video cassette recorder. There were no significant intraoperative or postoperative complications.

In 1933, Dr. C.I. Junkin ${ }^{1}$ reviewed his experience with spinal anaesthesia at The Hospital for Sick Children, Toronto, Canada. Now 52 years later, we have reviewed our experience with a similar technique for minor paediatric surgery at the same institution.

\section{Methods}

Thirty-four patients (A.S.A. physical status I) aged from seven weeks to 13 years who were scheduled to have minor abdominal or lower extremity ortho-

\section{Key words}

ANAESTHESIA: paediatric; ANAESTHETIC TECHNIQUES, REGIONAL: spinal; ANAESTHETICS LOCAL: bupivacaine, tetracaine.

From the Department of Anaesthesia, The Hospital for Sick Children, University of Toronto, Toronto, Ontario. Presented at the International Anesthesia Research Society 59th Congress, Houston, Texas, March 1985. Address correspondence to: Dr. W.L. Roy, Department of Anaesthesia, The Hospital for Sick Children, 555 University Avenue, Toronto, Ont. M5G 1 X8. paedic procedures were anaesthetised by the spinal route. Approval and informed consent was secured from the parents of all patients. They were premedicated, when indicated, with diazepam $0.1 \mathrm{mg} \cdot \mathrm{kg}^{-1}$ p.o., two hours pre-operatively. Efforts to distract and comfort children over the age of two years included story-telling and/or Walt Disney cartoons played on a video-cassette recorder. Those younger than age two years received intravenous sedation (diazepam $0.1 \mathrm{mg} \cdot \mathrm{kg}^{-1}$ and/or fentanyl $2.0 \mu \mathrm{g} \cdot \mathrm{kg}^{-1}$ and were restrained during the lumbar puncture.

The L3-4 or L4-5 intervertebral space was identified. Following skin preparation and local infiltration with lidocaine (one per cent), a $1 \mathrm{~mm}$ slit was made in the skin with an 18 gauge needle. The subarachnoid space was then punctured with the patient in either the lateral or sitting position. In children under nine years of age, a hollow stylet from a 24 gauge angiocath was used; a 22 gauge spinal needle was used in older children. Either hyperbaric bupivicaine 0.75 per cent ${ }^{2}$ or tetracaine one per cent was used. These anaesthetic agents were not diluted prior to insertion into the subarachnoid space. An intravenous line was started in an anaesthetised foot and $6 \mathrm{ml} \cdot \mathrm{kg}^{-1}$ of lactated Ringer's solution ${ }^{3}$ was infused during the preparation and administration of the spinal anaesthetic.

All patients were monitored with a precordial stethoscope, blood pressure cuff, EKG, ultrasonic Doppler radial artery flow detector, stethoscope and axillary temperature probe. The level of analgesia was determined after leaving the patient supine for three minutes following injection of anaesthetic into the subarachnoid space. This level was determined by attempting to elicit a grimace or acknowledgement of pain to bilateral pin prick at each dermatome.

\section{Results}

Four of the 34 patients required general anaesthesia because of failure to locate the subarachnoid space. 
TABLE I Medications and doses used

\begin{tabular}{lcll}
\hline Tetracaine 1\% & $0-3$ months & 3 months -24 months & 24 months \\
& $0.4-0.5 \mathrm{mg} \cdot \mathrm{kg}^{-1}$ & $0.3-0.4 \mathrm{mg} \cdot \mathrm{kg}^{-1}$ & $0.2-0.3 \mathrm{mg} \cdot \mathrm{kg}^{-1}$ \\
Bupivicaine 0.75\% & $0-24 \mathrm{months}$ & 24 months & \\
& $0.3-0.4 \mathrm{mg} \cdot \mathrm{kg}^{-1}$ & $0.3 \mathrm{mg} \cdot \mathrm{kg}^{-1}$ & \\
\hline
\end{tabular}

TABLE II Supplementation of spinal anaesthesia

\begin{tabular}{|c|c|c|c|}
\hline & No sedation & $\begin{array}{l}\text { Minimal Sedation } \\
\text { fentanyl } 2 \mu \mathrm{\mu g} \cdot \mathrm{kg}^{-1} \\
\text { diazepam } 0.1 \mathrm{mg} \cdot \mathrm{kg}^{-1}\end{array}$ & $\begin{array}{l}\text { Light general } \\
\text { anaesthesia } \\
0.50 \%: \text { halothane } \\
\mathrm{N}_{2} \mathrm{O}, \mathrm{O}_{2} \text { by mask }\end{array}$ \\
\hline $\begin{array}{l}\text { Orthopaedic surgery } \\
18 \text { patients mean age: } \\
87 \text { mos } \pm 27 \text { mos }\end{array}$ & 7 patients & 6 patients & 5 patients \\
\hline $\begin{array}{l}\text { Low abdominal surgery } \\
12 \text { patients mean age: } \\
44 \text { mos } \pm 40 \text { mas }\end{array}$ & 0 patients & 6 patients & 6 patients \\
\hline
\end{tabular}

A failure was defined as two unsuccessful attempts at lumbar puncture. In the remaining 30 patients, 18 underwent orthopaedic procedures of the lower extremities and 12 underwent minor abdominal surgical procedures. The dose given of tetracaine one per cent ranged from $0.2-0.5 \mathrm{mg} \cdot \mathrm{kg}^{-1}$; bupivicaine 0.75 per cent varied from $0.3-0.4 \mathrm{mg} \cdot \mathrm{kg}^{-1}$ (Table I). The level of anaesthesia obtained varied from to T-12 to T-4 with a mean of T-7 for the 30 patients. If the patient was uncooperative a sedative was given intravenously. Either fentanyl $2 \mu \mathrm{g} \cdot \mathrm{kg}^{-1}$ or diazepam $0.1 \mathrm{mg} \cdot \mathrm{kg}^{-1}$ was used. Six patients in the orthopaedic group and six in the abdominal surgery group needed sedation.

A further five patients in the orthopaedic group and six in the abdominal surgery group required general anaesthesia. In the orthopaedic group, general anaesthesia was required because the procedure outlasted the spinal anaesthetic (Table II). In the abdominal surgery group general anaesthesia was required because relaxation was inadequate in two patients, and peritoneal retraction caused pain in four patients. There were no intraoperative episodes of hypotension (systolic pressure 15 torr below ward levels), arrhythmias or vomiting. Postoperatively, one patient suffered from post-spinal headache, associated with meningismus, nausea and vomiting. This patient was treated with IV fluids and analgesics. He was discharged in good health after three days.

\section{Discussion}

We agree with Melman et $a l^{4}$ that the use of spinal anaesthesia in infants and children should be limited to operations of the lower abdomen and lower extremities. Junkin ${ }^{1}$ used spinal anaesthesia in four cases of thoracic surgery. The improvement of general anaesthesia in $\mathbf{5 0}$ years has eliminated the need for this technique in such cases.

Junkin's ${ }^{1}$ choice of local anaesthetic was novocaine 1-2 mg $\cdot \mathrm{lb}^{-1}$. A recent paediatric anaesthesia text $^{3}$ suggests the use of lidocaine five per cent in a dose of $1-2 \mathrm{mg} \cdot \mathrm{kg}^{-1}$ or tetracaine one per cent in a dose of $0.2 \mathrm{mg} \cdot \mathrm{kg}^{-1}$. Abajian et al. ${ }^{5}$ in a review of spinal anaesthesia in infants recommended tetracaine in a dose of $0.25 \mathrm{mg} \cdot \mathrm{kg}^{-1}$ and our experience corroborates his recommendation in older children. The doses and drugs we have used appear to be adequate for orthopaedic procedures of short duration. Our success rate in abdominal surgery was not as impressive. Larger doses and volumes are required, particularly when the peritoneum must be retracted. It is essential that a young patient remains comfortable and co-operative throughout the procedure.

Junkin ${ }^{1}$ points out that the main difficulty in the use of spinal anaesthesia in infants is locating the subarachnoid space and injecting the anaesthetic drug. The neonatal spinal cord can end anywhere from T12 to L3. Therefore, we generally attempt our lumbar puncture at $\mathrm{L} 4$ or $\mathrm{L} 5$ interspace. The 
depth of the subarachnoid space is approximately $1.0-1.5 \mathrm{~cm}^{3}$ in the neonate at the $\mathrm{L} 4$ interspace. Once the needle has penetrated the subarachnoid space and adequate flow of C.S.F. has been demonstrated a short IV extension ( $T$ connector Medex Inc.) and syringe were attached to the hub of the lumbar puncture needle. This $T$ connector lessens the drag on the spinal needle and reduces the likelihood of extradural injections.

Junkin used heavy preoperative sedation, Singler $^{3}$ suggested rectal or intravenous barbiturates, narcotics and sedatives or light general anaesthesia, while Melman ${ }^{4}$ administered ketamine intravenously.

Patients who were sedated (Table II) during the procedure were either awake or sleeping comfortably. On completion of surgery, they were all analgesic, awake and co-operative. In our view, this group represented a satisfactory result. In older children we used a collection of Disney cartoons played on a video cassette system. The children were distracted by this method both during the actual lumbar puncture and subsequently throughout the operative procedure. In the absence of a video system they were entertained with books read to them by helpful operating room staff.

It is difficult to detemine the level of analgesia in infants; our method was to elicit a response to a painful stimulus at each dermatome. Berkowitz et $a l .{ }^{6}$ reported that such a method is unsatisfactory in children because it is both unreliable and disturbing. They preferred to observe the progress of paralysis in the anterior or lateral abdominal muscles as the child cried, talked or coughed. The paralysed muscles bulged outward while the non-paralyzed muscles contracted inward during expiration. Since the level of analgesia is a few dermatomes cephalad to the level of muscular relaxation, the anaesthetist can be more certain of the analgesic level by using this method.

The duration of surgery is a further limitation to the use of spinal anaesthesia in children. Five orthopaedic cases which lasted longer than 70 minutes required the addition of general anaesthesia ( $\mathrm{N}_{2} \mathrm{O} / \mathrm{O}_{2}$ halothane by mask) in order to complete the procedure. In the abdominal surgery group, six patients required a similar general anaesthetic due to inadequate relaxation or discomfort during peritoneal retraction. Junkin' noted that "light supplementary anaesthesia with gas and oxygen was found necessary in a few cases to control apprehensive children and in a number of cases where the operation was prolonged beyond the expected time." Light general anaesthesia was required in 33 per cent of our cases (Table II).

Those patients who required general anaesthesia could be viewed by some as a failure in technique. However, anaesthesia provided by the spinal anaesthetic and the administration of 0.5 per cent halothane, $\mathrm{N}_{2} \mathrm{O} / \mathrm{O}_{2}$ facilitated the completion of surgery. Generally, these patients awakened rapidly and were extremely comfortable as a result of the residual spinal analgesia. Those procedures which outlasted the spinal anaesthetic, necessitating the administration of a general anaesthetic, could best be avoided in the future. Better selection of surgical procedures, administration of epinephrine in combination with the local anaesthetic and a request for more time efficient surgery could lead to the avoidance of unnecessary general anaesthesia.

Junkin ${ }^{1}$ did not observe any instances of alarming hypotension in the face of little or no intravenous hydration. Hypotension did not occur in our series. However, we did prehydrate our patients intravenously as Singler ${ }^{3}$ has recommended. Post-spinal headache occurred in two patients in the series reported by Junkin; one of our patients had this complication. Following this one spinal headache, we began using the hollow stylet from a 24 gauge angiocath in children under the age of nine years. No further postspinal headaches were noted.

In fifty years many changes have taken place in the practice of anaesthesia. Due to advances in general anaesthetic agents and techniques, the need for improvement in spinal anaesthesia in children has been unnecessary. Thus, the art and the science of spinal anaesthesia in paediatric patients have been neglected. Our hospital has been no exception; from the above series one can see that we encountered our share of difficulties. However, with continued persistence in using this technique many of these problems should be solved. When skilled personnel are available in combination with knowledgeable assistants, the results are generally satisfactory. When any of these factorsare absent, the technique will probably fail. Our series shows that with careful management the technique remains a viable option. 


\section{References}

1 Junkin CI. Spinal anaesthesia in children. Can Med Assoc J 1933; 51-3.

2 Moore DC. Spinal anesthesia: bupivacaine compared with tetracaine. Anesth Analg 1980, 59: 743-50.

3 Singler $R C$. Pediatric regional anesthesia. Pediatric Anesthesia 1983, vol. 1, p. 481. Ed. George A. Gregory. Churchill Livingstone, New York.

4 Melman E. Penuelas JA, Marrufo JE. Regional anesthesia in children. Anesth Analg 1975, 54 : 387-90.

5 Abajian JC, Melish R.W.P., Browne AF, Perkins $F M$, Lambert DH, Mazuzan JE. Spinal anesthesia for surgery in the high-risk infant. Anesth Analg 1984; 359-62.

6 Berkowitz $S$, Greene BA. Spinal anesthesia in children: report based on 350 patients under 13 years of age. Anesthesiology 1951, 12: 376-87.

\section{Résumé}

Notre expérience récente dans l'utilisation de l'anesthésie rachidienne pour des procédures chirurgicales en pédiatrie est revue. En 1984, 30 patients âgés de sept semaines d 13 ans ant été anesthésiés de cette façon. La ponction lombaire était impossible dans quatre des 34 patients, 12 ont requis une sédation pendant la procédure chirurgicale et 11 ont requis une anesthésie générale légère afin de compléter cette procédure. La tétracaine 1.0 pour cent ou la bupivicaine 0.75 pour cent ont été les drogues utilisées. Pendant la procédure et selon l'age les patients ont été soit sédationnés soit distrayés par l'utilisation de "Disney cartoons" joué sur une enregistreuse vidéo-cassette. Il y a eu aucune complication significative pendant et après l'opération. 